\title{
On Direct Nuclear Divisions in the Vegetative Mycelium of Saprolegnia.
}

\author{
BY \\ FRANCIS E. V. SMITH. \\ With twelve Figures in the Text.
}

GINCE de Bary began his well-known researches on the cytology of the $S$ Saprolegniaceae, this subject has been studied by many investigators, the majority of whom have been mainly concerned with the sexual organs. Those who have studied the cytology of the vegetative organs have investigated the phenomena associated with the formation of zoospores (Hartog, 1887, 1895 ; Rothert, 1890 ; Trow, 1895).

Trow and Hartog both described nuclear divisions in the vegetative portions of the mycelium, but while Hartog saw a form of mitotic division, in which four granular chromosomes appeared and spindles were absent, Trow was unable to observe anything comparable to this, finding only amitosis.

The following investigation was therefore undertaken with the object of ascertaining the actual process of nuclear division.

\section{ISOLATION OF THE FUNGUS.}

The fungus was found growing on flies in the pond of the Bristol University Botanic Garden. From the mixture of fungi present a welldeveloped sporangium of Saprolegnia was teased out with fine forceps. After being washed several times in distilled water it was shown on microscopical examination to be free from zoospores and stray pieces of mycelium. It was then transferred to a Petri dish containing beef gelatine and the dish was tilted at an angle of $30^{\circ}$, and thus the infusoria and bacteria were drawn away from the fungus (Lechmere, 1910), which was finally transferred to sterilized flies floating on well-aerated, distilled water. To reduce bacterial growth to a minimum the water was changed every two days.

[Annals of Botany, Vo1. XXXVII. No. CXLV. January, 1923.]" 


\section{IDENTIFication of the Species.}

The species does not correspond exactly with any of those described in Rabenhorst's 'Flora', and it is considered to be a hybrid which shows affinities to at least three recognized species, but resembles most closely S. dioica, of which it is considered to be a variety possessing stouter hyphae and fewer antheridia. The antheridia are produced on separate branches, thus indicating that it is very closely allied to that species. The relations of its characteristics to various species are given in the following table:

Size of hyphae

Form of oogonium

Size of oospheres

Number of oospheres

Antheridia

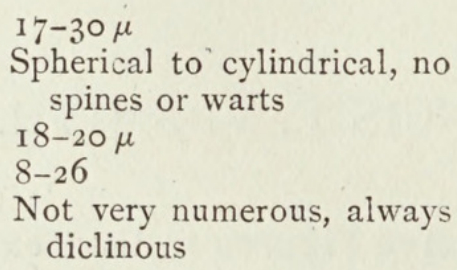

Not very numerous, always diclinous

S. torulosa and Lechmere's sp.

$S$. torulosa, $S$. dioica, and Lechmere's sp.

Any species.

$S$. dioica and $S$. torulosa.

S. dioica.

\section{TECHNique.}

The discovery of a good fixative was a matter of some difficulty. The outer walls of the hyphae are very thin, and unless fixation was instantaneous plasmolysis resulted, with the consequent shrinkage of the cytoplasm. The most satisfactory liquids were Merkel's solution and a modification containing acetic acid :

$\begin{array}{llllr}\text { Acetic acid }(5 \text { per cent.) } & . & . & . & \text { I00 parts. } \\ \text { Platinic chloride (I per cent.) } & \cdot & . & . & 5 \text { parts. } \\ \text { Chromic acid (I per cent.) } & \cdot & . & . & \text { IO parts. }\end{array}$

This gave excellent results, both in quickness of killing and in preservation of the nuclei, especially when used at $70^{\circ} \mathrm{C}$.

During the fixing and washing processes it was most convenient to handle the material while still attached to the fly. After the flies had been washed in 50 per cent. alcohol for six hours they were placed in water and the mycelium scraped off with needles. At this stage the hyphae were fixed to the slide, by using a thin film of Meyer's fixative; very little was required, as an excess absorbed the stain and thus lowered the value of the preparations. The hyphae were placed in a drop of water on the prepared slide and dried in an incubator. Care had to be taken to prevent all the water from evaporating, though if too much water were left all the hyphae floated off again. At the right moment the slides were placed in 70 per cent. alcohol for two minutes, thus permanently fixing the material to the glass. From the 70 per cent. alcohol they were placed in water and were then ready for staining. By this method the long delay experienced by Hartog was obviated.

Those who studied the sexual organs used microtome sections, but 
it was found that in the case of the vegetative hyphae many sections were lost through imperfect adhesion to the slide. A much better idea of the state of the hyphae was obtained by mounting them whole, and no difficulty was found in examining them. Three methods of staining were used: Flemming's triple stain, iron-haematoxylin, and Delafield's haematoxylin, though it was found necessary to alter the usual times recommended for the first of these. The slides were removed from water to a saturated solution of aniline-water-safranin, where they were left for three to six hours. They were then treated thus: water three minutes, gentian violet (aqueous) thirty minutes, water one minute, orange $G$ (aqueous) one minute, 90 per cent. alcohol one minute, roo per cent. alcohol one minute, clove oil five minutes, benzol, Canada balsam. Although the process of taking the material from water to 90 per cent. alcohol may seem very drastic, in only a few cases did shrinkage of the cytoplasm take place to any appreciable extent, and, since the stain was only used for the nuclear figures, this did not matter. Xylol as a clearing agent seemed to cause too great a shrinkage of the cytoplasm, and so benzol was substituted.

\section{Cytological Observations.}

In the early stages the floating hyphae are slender and contain a mass of dense cytoplasm with small vacuoles. They grow rapidly in breadth until they have reached the normal thickness, by which time the cytoplasm has been reduced to a thin peripheral layer. The intramatrical hyphae, on the other hand, are very poor in cytoplasm.

Protein granules constitute the main portion of the cytoplasm, and show very distinctly in stained preparations. In living material they are visible under high-power objectives, and seem to be constantly moving, both in streaming and in Brownian movement. Cytoplasmic streaming is continuous, chiefly in the direction of the apex, though slight back currents occur. It appears that the tendency is to form zoosporangia, for, when the accumulation of cytoplasm at the apex has become sufficiently dense, a septum is formed and a zoosporangium cut off. As soon as the cytoplasmic continuity is thus broken, fresh cytoplasm accumulates below the septum, so that, by the time the zoospores have formed and escaped, sufficient cytoplasm and nuclei have accumulated below the septum to fill the empty zoosporangium case completely. All that remains is for the septum to grow upwards into the old sporangium and the cytoplasm immediately below follows.

In one instance a count of nuclei was made in a preparation treated with Flemming's stain, in which the zoospores were about to escape from the sporangium. The cytoplasm for a distance below, of about the length of a sporangium, was practically as dense as that in the zoospores. The 
number of nuclei in this part was between 270 and 280 , while the number of uninucleate zoospores was about 280 ; this shows that no nuclear divisions take place in the sporangium.

The cytoplasm in the upper parts often appears frothy. Throughout the plant are found occasional granules of the cellulose-like substance to which Pringsheim gave the name of cellulin, since it gives most of the reactions of cellulose.

The nuclei are very numerous in the hyphae, but always occur in much

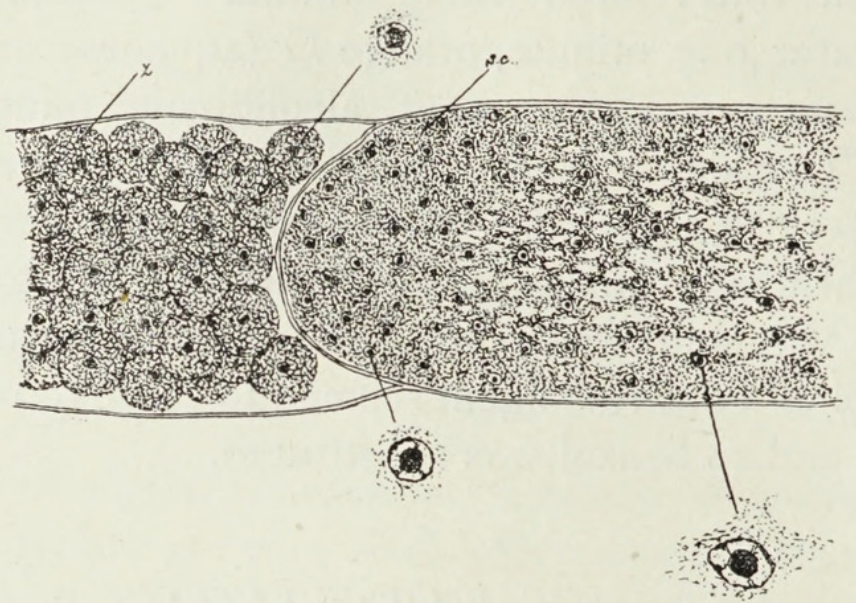

FIG. I. The apical sporangial region of a hyphal filament, showing the dense cytoplasm, s.c., and spherical nuclei. $z$, zoospore. $\times 500$ and $\times 1,500$.

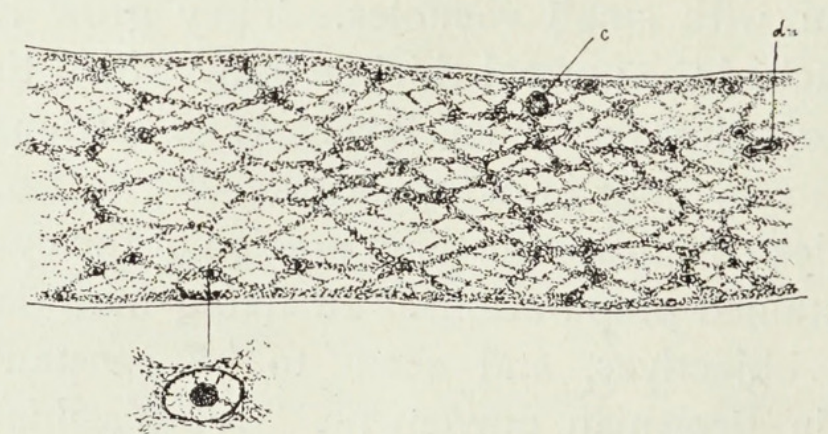

FIG. 2. The middle portion of a hypha, showing two kinds of cytoplasmic strands and elongated nuclei. Most of the nuclear divisions occur in this region. d.n., dividing nucleus; c., cellulin body. $\times 500$ and $\times \mathrm{I}, 500$.

greater numbers towards the tip, whither they are carried by the rapidly streaming cytoplasm. The typical nucleus is spherical in shape, but both shape and size vary according to the position in the plant (Figs. $\mathrm{I}-3$ ).

The main portion of the nucleus consists of a central body which stains very deeply with all nuclear stains. Surrounding this is a layer of nucleohyaloplasm which is bounded externally by a distinct nuclear membrane, which in all good preparations is found to be of uneven thickness, due to the presence of granules of chromatin; these granules are not evenly distributed, but usually appear as occasional mounds upon the nuclear membrane (Figs. 4 and 5). The central body is suspended within the nucleus by fine linin threads arising in most cases from the chromatin granules on the 
nuclear membrane. This central mass consists mostly of chromatin, and appears at first to be a nucleolar body. It is comparable with a similar body found in the vegetative nuclei of Penicillium, to which Guéguen (1899) applied the indefinite term 'chromoblast', as the function of this body is not yet realized. Its shape is usually spherical or ovoid, but in a few cases it is slightly flattened to a disc-like form. In some lightly stained preparations it appears to be fluid within, with a more deeply stained outer coat.

In examining a long hypha of the fungus, it was noticed that the nuclei are neither uniform in shape nor size, but that there is a gradual transition in shape from a spherical form in the zoosporangium to a long torpedo-like form in the lower parts of the thallus.

In the zoospore the cytoplasm is dense and fairly evenly distributed,

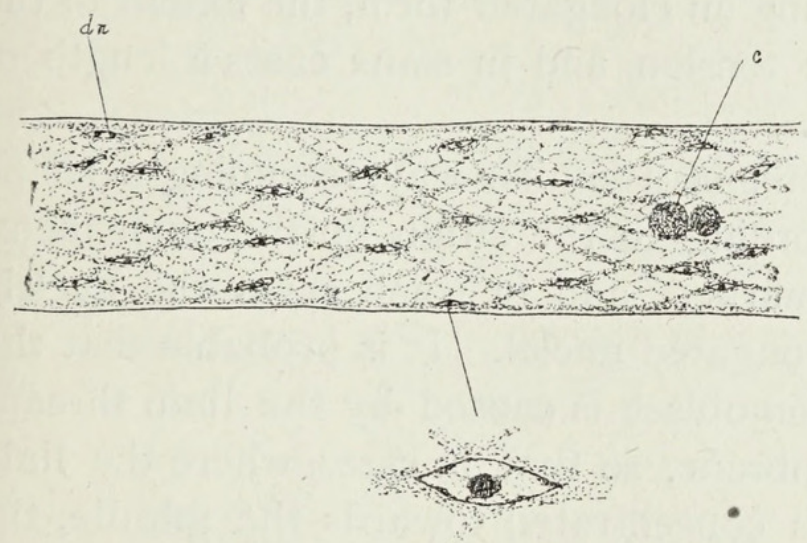

FIG. 3. The base of a hypha, where the cytoplasm is much less dense. The nuclei are long and pointed at the ends. $\times 500$ and $\times 1,500$. d.n., dividing nucleus; c., cellulin body.

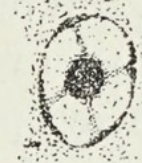

FIG. 4. A typical resting nucleus, splierical in shape, with pronounced linin threads and granules on the membrane. $\times 3,000$.

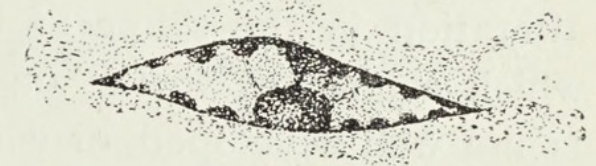

FIG. 5. An elongated form showing chromatin on the membrane. $\times 3,000$ 。

and the nucleus spherical, the central body of which constitutes the main portion. The hyaloplasm is not so broad as in the other parts and less chromatin is present on the outer membrane. The size is about $3.5 \mu$ in this condition, which is considered to be the resting condition. A similar state of affairs is found immediately below the septum, where the cytoplasm is also quite dense; in these nuclei the hyaloplasmic layer is slightly deeper (Fig. I). A short distance below this region the cytoplasm becomes less dense, and there is a rapid transition from the homogeneous condition just described to a state in which strands appear in the cytoplasm. These at first are quite close together, consisting of dense cytoplasm with nuclei distributed within them. Between the main strands, which, because of the rapid streaming, run chiefly longitudinally and diagonally, is a network of finer strands. The latter form connexions between the neighbouring main strands, and some cross the lumen and connect the cytoplasm on opposite sides of the hypha. The quantity of cytoplasm gradually becomes less in the lower parts, so that 
the strands are fewer in number, although the density of each is not greatly lessened (Fig. 3).

The constant upward streaming seems to cause a tension or strain within the semi-liquid cytoplasm. This strain is apparently transmitted throughout the length of the hypha, with the result that in the less dense portions at the base the strain is the same as in the apex. As, however, the cytoplasm is denser in the apex, the effect on each individual strand is not so great here. In the basal portions the strands are fewer, with the result that each is in a state of greater tension. The nuclear membranes are in close contact with the cytoplasm, so that the tension in the cytoplasm is transmitted to the nuclei, which, being of a plastic nature, respond to the strain by becoming elongated. In the hyphal tips where the cytoplasm is evenly distributed, the tension is equal on all sides, with the result that the nucleus is spherical. Where the cytoplasm is in a state of greater longitudinal strain the nuclei respond by assuming an elongated form, the extent of the elongation being proportional to the tension, and in some cases a length of $6 \mu$ with a breadth of $2 \mu$ is attained.

The central nuclein body responds in a similar way, assuming a shape varying from spherical to oval according to the strain on the outer membrane; but the change is not so marked, and in some cases the nuclein retains its spherical shape even in elongated nuclei. It is probable that the alteration in the shape of the chromoblast is caused by the linin threads which connect it to the outer membrane, so that in cases where the linin is not well developed, or where it is concentrated towards the middle, the spherical form is retained.

\section{Amitosis.}

No nuclear divisions take place in the zoosporangium, nor in the region just below the septum, but they are found chiefly in the region of the middle of the hypha, and below this.

In every case the nuclei in the vegetative hyphae were found to divide by a direct division. In the oogonium, mitotic divisions have been observed by Hartog, Trow, Davis, and Claussen, but the writer has not discovered anything comparable to spindle fibres or chromosomes in the vegetative nuclei.

The division begins with an elongation of the chromoblast, the membrane remaining intact until the end of the division. The chromatin granules on the membrane and the linin threads are visible throughout the whole process. After the chromoblast has elongated slightly the nuclear membrane becomes larger. A median constriction then appears in the chromoblast, and after a short time a similar constriction begins in the membrane (Fig. 6). Elongation of both parts continues throughout the whole process, with the result that the constrictions become gradually more 


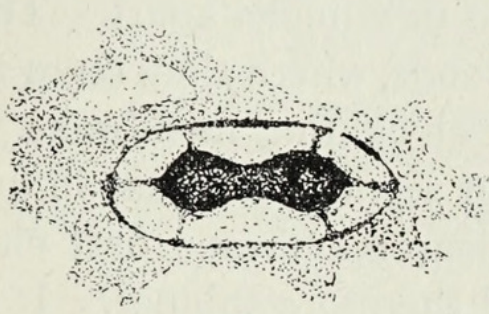

Fig. 6.

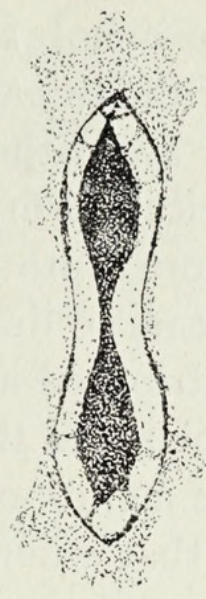

FIG. 7.

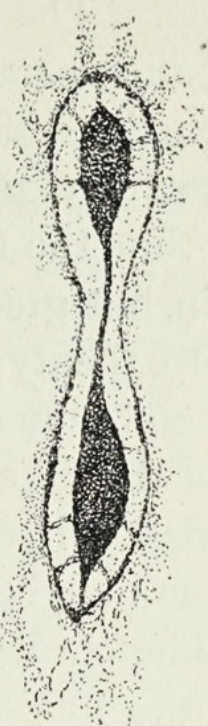

FIG. 8.

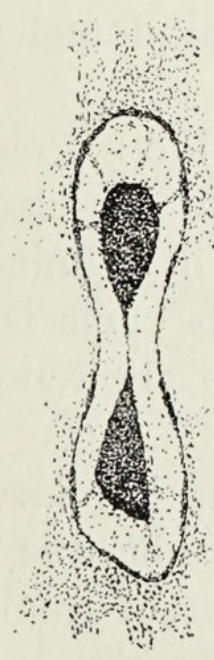

FIG. 9.

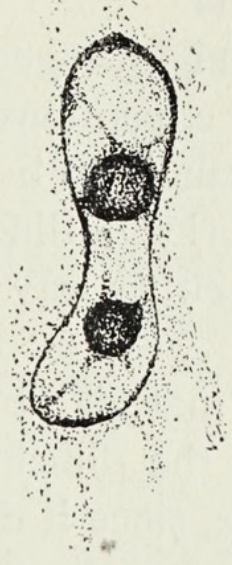

FIG. IO.

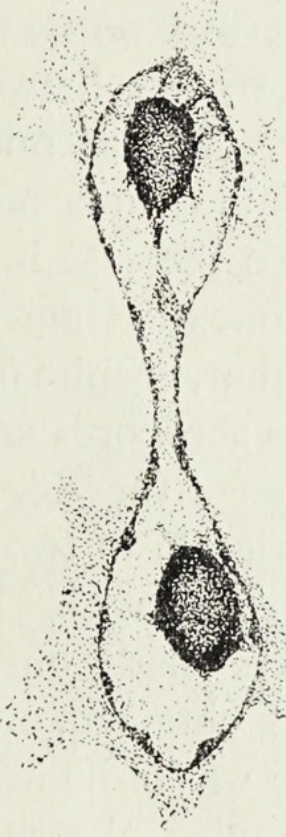

FIG. 1 I.

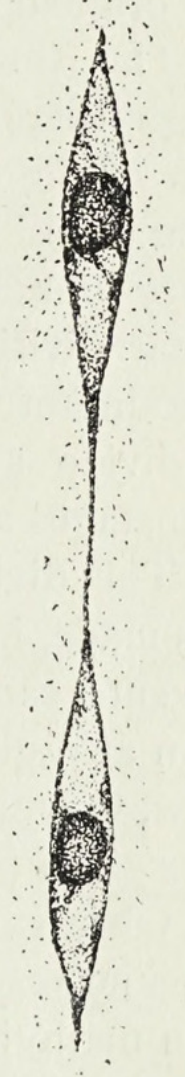

FIG. I 2.

FIG. 6. The first stage in the amitotic elongation of the chromoblast. $\times 3,000$.

FIG. 7. The second stage in the division. $\times 3,000$.

FIG. 8. The third stage. The chromoblast is constricted in the middle and is still elongating. $\times 3,000$.

FIG. 9. The fourth stage. The two daughter chromoblasts are now joined only by a thread. $\times 3,000$.

FIG. Io. The fifth stage. The two daughter chromoblasts have separated and have assumed the spherical form once more. $\times 3,000$.

FIG. II. The sixth stage. The nuclear membrane has become more constricted and the whole nucleus longer. The chromatin on the membrane has regained its original density. $\quad \times 3,000$.

FIG. I 2. The two daughter nuclei are about to separate. $\times 3,000$. 
marked. The parts of the nucleus farther away from the constrictions remain about the normal width, but the centre becomes gradually thinner until the two portions of the chromoblast are finally joined only by a thread (Fig. 9), at which stage the outer membrane appears hour-glass-shaped. For a short time the remnants of the thread joining the two daughter chromoblasts remain, but gradually they are withdrawn into the new bodies, which round off into the typical spherical form (Figs. IO and II). The constriction of the membrane becomes more acute until the two sides touch. Finally, the pull of the cytoplasm appears to draw the two new nuclei apart. The linin threads are irregularly distributed at the two ends, where they seem to hold the two daughter chromoblasts to the rapidly elongating membrane.

The chromatin on the membrane does not seem to increase in quantity until the final stages, so that when the nuclear membrane first elongates these chromatin masses become stretched and therefore thinner. It is only after the daughter nuclei start to round off again that these slowly regain their original density (Fig. II).

The time at which nuclear division takes place is fairly constant, though there is reason to believe that a few divisions take place at all times of the day and night. From the results obtained from a series of preparations which were fixed at every thirty minutes throughout the twenty-four hours, it can be stated that the majority of the vegetative nuclear divisions take place between the hours of 10 p.m. and 2 a.m., a maximum being reached at midnight. All the nuclei in a hypha do not divide at the same time, and in any case are not all found in the same stages as is often the case in oogonia.

This division about the time of midnight, together with other observations made, indicate that, in spite of many exceptions, there is a regular cycle of events, causing the zoospores and sporangia to be found in a similar condition at a given time of the day. A brief outline of this cycle is given below, in which a variation of two hours either way may be allowed on the times given (see opposite page).

Observations were made on living material, but in the hyphae themselves no results were obtained, owing to the difficulty of seeing the nuclei. Even methylene blue was of no assistance, since it did not stain evenly, and the cytoplasmic granules absorbed most of the stain. In the zoospore better results were obtained, and in a germinating specimen a number of divisions were seen during the night. No nuclear structure was visible, but constrictions in the nuclei were observed, and when the material was stained with iodine some eight or nine nuclei appeared. The cytoplasm streamed all the time, and with it the nuclei moved rapidly. The germtube had a dense mass of cytoplasm in the tip, but the nuclei remained in the zoospore for some time. When branching was about to take place in the young hypha, a nucleus was found in the neighbourhood of the branch origin. 
Time.

I 2 noon

4 p.m.

4.30 p.m.

10 p.m. to 3 a.m.

5 a.m.

6 a.m.

6.30 to 7 a.m.

7 to il a.m.

I I a.m. to I 2 noon.
Zoosporangium.

Spores germinate.

Septum growing upward.

Ditto.

Septum still growing, nuclei lower in the hypha divide, to be carried upward for the next sporangium on the next day.

Old sporangium filled by outgrowth of septum.

Cytoplasm ceases to flow into new sporangium.

Septum formed and cytoplasmic continuity broken.

Zoospore origins formed and zoospores round off.

Zoospores escape.
Zoospore.

Liberated.

Second motile stage.

Reaches host and germinates.

Movement of cytoplasm rapid, germination advancing, nuclei divide sufficiently to serve the hypha next day.

Germ-tube lengthens, branches formed, no more nuclear divisions.

The vegetative nuclei can be stimulated to division at any time of day. A culture is placed in a very cold greenhouse for two days, where the water can be kept at about $4^{\circ} \mathrm{C}$. The flies are then suddenly removed to water at $22^{\circ} \mathrm{C}$., and are left at that temperature, which is a little above the optimum, for from ten to twenty minutes. The material is then fixed with hot acetic Merkel's solution. Nuclear figures can usually be produced in this way; they are always amitotic.

\section{Discussion.}

Hartog and Trow, who have both studied the nuclei of the vegetative hyphae of Saprolegnia, disagree on the method of division. The latter states that a direct division takes place in the zoospore, but in his figures this is not well shown. Hartog describes a rudimentary mitosis which he calls a transition between a direct and an indirect division. He saw four small granular chromosomes, which split longitudinally and then separated, no spindles being present. His figures are not distinct, and it is difficult to see how he could have observed such small granules splitting longitudinally without staining them; in only one or two figures is it possible to distinguish the four chromosomes. No similar figures were seen during this investigation.

If the division is by the indirect method, the chromatin granules should have a part in chromosome formation. Here, however, the membrane remains intact during the division of the chromoblast, and only separates in the last stages when the chromatin has divided. The fact that the linin threads remain attached to the chromoblast througnout the 
division is further evidence in favour of direct division. It is possible that both forms occur, for in Valonia Fairchild (1894) describes both mitotic and amitotic divisions.

Amitosis has been found in the vegetative mycelia of several of the fungi, notably in Penicillium (Guéguen, 1899) and the yeasts (Wager, 1898, and Guilliermond, 1903). Guilliermond also figured amitosis in Mucor, and this compares very favourably with that described above. The nucleus in yeast has a very different construction from that in Saprolegnia, and consequently cannot be compared, but the division described for Penicillium appears to be very similar to that described in this paper.

The type of amitosis in Saprolegnia is not a mere fragmentation, but it is an ordered division somewhat allied to that described for the nucleus of Ancylistes by Dangeard (1903). This nucleus, however, has a true nucleolus which passes out of the membrane as division commences. The chromoblast in Saprolegnia has not a true nucleolar function, since it takes an active part in the division.

\section{SumMary.}

I. The fungus investigated appears to be a variety of Saprolegnia dioica. The vegetative nuclei are typically spherical, but vary in size and shape according to the concentration of the cytoplasmic strands and the consequent tension exerted by them.

2. Only amitotic divisions of the vegetative nuclei have been observed during the course of this investigation.

3. As a rule the nuclei divide between 10 p.m. and 2 a.m., but they can at any time be stimulated to division by removing the fungus from very cold water to water at $20^{\circ}$ to $22^{\circ} \mathrm{C}$.

The writer wishes to express his thanks to Professor O. V. Darbishire for suggesting the subject of this investigation and giving much helpful advice and criticism while it was being carried out.

\footnotetext{
Cryptogamic Research Laboratory,

Department of Botany, University of Bristol, July 1922.
} 


\section{LITERATURE CITED.}

Claussen, P. (1908): Über Eientwickelung und Befruchtung bei Saprolegnia monoica. Ber. d. deut. Bot. Ges., vol. xxvi, p. I 44 .

DANGeard, P. (1903): La Sexualité chez les Champignons. Le Bot., sér. 9.

Davis, B. M. (1903) : Oogenesis in Saprolegnia. Bot. Gaz., vol. xxxv, p. 23 .

FAIRCHILD, D. G. (1894): Beitrag zur Kenntniss der Kerntheilung bei Valonia utricularis. Ber. d. deut. Bot. Ges., vol. xii, p. 33 I.

GuÉGuen, F. (1898-9): Recherches sur les organismes mycéliens des solutions pharmacentiques. Bull. Soc. Myc. France, vol. xiv, pp. $20 \mathrm{I}-5^{2}$; vol. xv, pp. I $5-36$.

Guilliermond, 'A. (1903) : Recherches sur les levures. Rev. Gén. de Bot., vol. xv, pp. 49-67, 104-25, I 66-86.

(1914)': Progrès de la cytologie des Champignons. Progr. Rei Bot., vol. iv, p. 389 .

Hartog, M. M. (1887): On the Formation of the Zoospores in Saprolegnia. Quart. Journ. Micro. Sci., vol. xxvii, p. 427 .

(1895): On the Cytology of the Vegetative and Reproductive Organs of the Saprolegniaceae. Trans. Roy. Irish Acad., vol. xxx, Part XVII.

Lechmere, A. E. (1910): Investigation of a Species of Saprolegnia. New Phytol., vol. ix, p. 305. Rothert, W. (1890): Die Entwickelung der Sporangien bei den Saprolegnieen. Cohn's Beitr. zur Biol. d. Pflanzen, vol. v, p. 291.

Trow, A. H. (1895) : Karyolngy of Saprolegnia. Ann. Bot., vol. ix, p. 609. (1899): Observations on a New Variety of Achlya Americana. Ibid., vol. xiii, p. I 3 I.

Wager, H. W. T. (1898): Nucleus of the Yeast Plant. Ibid., vol. xii, p. 449. 


\section{$2 \mathrm{BHL}$ Biodiversity Heritage Library}

Smith, Francis E. V. 1923. "On direct nuclear divisions in the vegetative mycelium of Saprolegnia." Annals of botany 37, 63-73.

https://doi.org/10.1093/oxfordjournals.aob.a089837.

View This Item Online: https://www.biodiversitylibrary.org/item/270686

DOI: https://doi.org/10.1093/oxfordjournals.aob.a089837

Permalink: https://www.biodiversitylibrary.org/partpdf/319068

\section{Holding Institution}

New York Botanical Garden, LuEsther T. Mertz Library

\section{Sponsored by}

BHL-SIL-FEDLINK

\section{Copyright \& Reuse}

Copyright Status: Public domain. The BHL considers that this work is no longer under copyright protection.

This document was created from content at the Biodiversity Heritage Library, the world's largest open access digital library for biodiversity literature and archives. Visit BHL at https://www.biodiversitylibrary.org. 